\title{
Relationship between Participants Satisfaction in Agro-Healing Activities in a Healing Farm and the Level of Stress and Loyalty
}

\author{
Hye Sook Jang, Sun-Jin Jeong, Jae Soon Kim, and Eunha Yoo* \\ Researcher, Urban Agriculture Research Division, National Institute of Horticultural and Herbal Science, Wanju-gun 55365, Korea
}

\section{ABSTRACT}

Background and objective: This study was conducted to find out the effects of healing farm resources and participant satisfaction on the level of stress and loyalty.

Methods: The experiment was conducted on 18 subjects who participated in agro-healing activities (aged 49.5 years on average) and the concentration of cortisol, the level of stress and satisfaction with the services and program of a healing farm. The healing-agriculture activities were performed once a week, a total of 7 sessions, for 90 minutes and their saliva was collected before and after the activities.

Results: The concentration of cortisol, a stress hormone, was statistically significantly reduced after the healing-agriculture activities in 5 out of 7 sessions. The total cortisol concentration showed statistically significant differences. The 6 th session was comprised of different activities, compared to others, such as understanding weeds, managing a garden and making a pizza with fermentation enzymes, and the level of cortisol in the 6th session was the lowest after participating in the agro-healing activities, which indicated that the activities have the positive effect of lowering the level of stress. The level of stress was lowered from 18.39 to 16.78, which was consistent with the results of the concentration of cortisol. The level of satisfaction in the last session was below 50\%, which indicated that the owner of the farm might be a little inexperienced in education and marketing on information and safety. The variables of participants including stress and satisfaction with services showed a strong influence on their loyalty.

Conclusion: Satisfaction with services and loyalty to the healing farm showed a very high correlation, which was statistically significant. It also showed that participants' stress level and satisfaction with the services and program of the healing farm have a strong influence on their loyalty.

Keywords: enzymes, program satisfaction, salivary cortisol, service satisfaction

\section{Introduction}

The concept of healing as its original dictionary definition is "treating to cure an illness" and focuses on mental health, experience and human aspects instead of using scientific and technological approaches (Finkelstein, 2003). Unlike the heteronomous and deterministic meaning of treatment, the concept also focuses on autonomous and selective aspects (K.H. Kim, 2009). Ulrich et al. (1991) high- lighted the importance of social elements such as those that affect healing environments including environmental control issues and positive physical environments. Choi and Kim (2002) classified healing environment elements into elements related to human, space and behaviors. Healing can be divided into two areas: healing as a role of protecting, complementing and preventing prior to the occurrence of emotional and physical damage; and healing as recovery, that is, treating trauma caused by accidents or severe men-

This study was supported by the 2019 Horticultural and Herbal Science Program of the National Institute of Horticultural and Herbal Science of the Rural Development Administration (PJ01137604).

Received: July 14, 2020, Revised: July 27, 2020, Accepted: August 3, 2020

First author: Hye Sook Jang, jhs915@korea.kr, (D) https://orcid.org/0000-0003-3011-8694

*Corresponding author: Eunha Yoo, galaxyoo@korea.kr, (1) https://orcid.org/0000-0002-5794-2600 
tal and physical stress. The fundamental problems that threaten the physically or mentally stable state of humans and fundamentally can be caused by the stress that the humans experience (Kwon, 2015). People are exposed to various types of stress, which makes them unable to adapt to modern society or experience disorders (Davis and Emory, 1995). Severe or long-lasting stress causes mental instability and conflicts and poses continuous tension on the autonomic nervous system, and this often causes mental and physical disorders or diseases (McKenzie-Mohr et al., 1995). Moreover, stress occurs in interactions between human and environment when the demand of the environment exceeds the capabilities of humans or when the demand of humans is not met by the environment. When this kind of stress or tension is not addressed or repeatedly occurs and lasts for a long time, this adversely affects psychological aspects such as depression and anger, physical aspects such as mental diseases and a decrease in immune function, and behavioral aspects such as aggression and overeating (Im, 1997). When humans recover from stress, however, positive emotions increase and negative emotions are suppressed (Ulrich, 1986). Physical activities that connect with the nature instead of artificial environments have positive effects on the psychological state of humans such as improved self-esteem or physical and mental stability (Yamaguchi et al., 2006).

As the term, healing, started to emerge in Korean society recently, people's interest in mental and physical healing has increased, and society as a whole starts to pay more attention to agro-healing that connects agriculture and agricultural resources with people's happiness. Physical activities through agro-healing that gives people opportunities to contact with the nature allow to understand the important interactions between plant and human (Relf, 1990). Agrohealing using agriculture and rural environments such as plants, animals, landscapes and cultures may not be a pure therapy for the general public and the socially disadvantaged, but gives people comprehensive experiences with therapeutic values (Braastad et al., 2007). All the agricultural and rural elements including agricultural activities, natural environments and cultural and emotional exchanges between people can be agro-healing resources. Healing farms where these resources can be utilized offer services with the help of mental health experts and agro-healing programs with meaningful physical activities in order to assist people to overcome difficulties that they face (Loue, 2016). In other words, agro-healing programs are not just to provide simple physical activities, but are designed to reduce anger and fatigue and to increase self-efficacy through activities using crops or vegetables (Park and Kang, 2017). In this regard, an academic forum led by the Rural Development Administration was formed with agro-healing experts, administrators and other related officials in 2016 to institutionalize agro-healing, and the Agro-healing Research, Development and Promotion Act went through the National Assembly plenary session in March, 2020, which further raised interest in healing farms. As economic development and an increasing national income in modern society have improved the quality of life of people in modern society and have enriched their life, many people not only consider environments and differentiating factors in making decisions but also pay more attention to the level of services to be provided and want to receive services of higher quality. However, only few studies have been conducted on the programs of healing farms or the satisfaction of participants with services. Against this backdrop, this study aimed to examine changes in the level of salivary cortisol, a stress hormone, and the level of perceived stress (Korean version) before and after participating in agro-healing activities in a healing farm, and to measure and analyze the satisfaction of users with the services of the healing farm after participating in the agro-healing program. Based on the results, this study identified and suggested useful measures to continuously increase people's participation in agro-healing activities in healing farms by improving the effects of agro-healing activities on stress and satisfaction with programs and user services.

\section{Research Methods}

\section{Selection of participants}

To examine the effects of agro-healing activities on the level of stress that middle-aged participants experience, the level of salivary cortisol, a stress hormone, and the level 
of stress were measured. Participants were recruited online with the support of the Sejong Agriculture Technology Center. A total of 18 males and females (aged 48.5 \pm 7.55 years on average) were selected among those who were fully informed of the purpose of this study and measurement items and methods and voluntarily signed the research consent form. Their saliva was collected twice in each session at 3:30 p.m. before participating in agro-healing activities and at 5:30 p.m. after participating in the activities. They were instructed not to drink alcohol two days prior to collecting saliva, and were instructed to sleep long enough at the night before collecting saliva. Any beverages that contain caffeine including black tea, coffee and green tea, any beverages or foods that can stimulate saliva and smoking were prohibited two hours prior to conducting this experiment.

\section{Experiment materials and methods}

In this study, 4-5 participants were randomly grouped together and those in each of the four groups participated in agro-healing activities together (Fig. 1). Each group designed a vegetable garden $(1.5 \mathrm{~m} \times 3 \mathrm{~m})$ for agro-healing activities and about 10 species of horticultural plants were used in agro-healing activities such as raising vegetables and floricultural plants ranging from sowing indoor to harvesting, learning information required to perform agro-healing activities indoor and expressing themselves through activities such as cooking with fermented enzyme which the healing farm is specialized in.

\section{Physiological assessment of participants}

To assess the physiological conditions of participants, their salivary cortitol, a stress hormone, was measured, and their saliva was basically collected and measured at the same time before and after participating in each session of the agro-healing program (Choi et al., 2014). In this study, the Salivette System using a cotton roll was used to collect saliva. When collecting saliva using the system, the sample can be easily contaminated by the hands or air, and standardized processes were strictly followed to minimize contamination and accurately collect salivary samples (Schwartz et al., 1998). Salivary cortisol analysis was conducted using an ER HS SALIVARY CORTISOL kit (Salimetrics Inc. USA) and a VERSA Max Microplate Reader (Molecular device, USA) and the unit of analysis was $\mu \mathrm{g} / \mathrm{dL}$. The collected data are interpreted as follows: the higher the concentration of salivary cortisol, the higher the level of stress, and the lower the concentration of salivary cortisol, the lower the level of stress.

\section{Psychological assessment tools}

(1) Korean version of perceived stress scale

As a tool for assessing psychological characteristics, the Korean version of perceived stress scale was used. PSS-10 (Perceived stress scale) developed by Cohen and Williamson (1988) was translated by Baek (2010) into the Korean version of perceived stress scale (PSS:K). This scale is composed of 10 questions and the score of the questions that a participant marked was totaled and divided into four stages. The higher the total score, the higher the level of perceived stress. When the total score is lower than 13, it is Stage 1 (the level of stress is normal, and stressors themselves are not serious or are perceived as positive stress), and when the total score is 13 or higher, it is Stage 2 (respondents have already been affected by stress). When

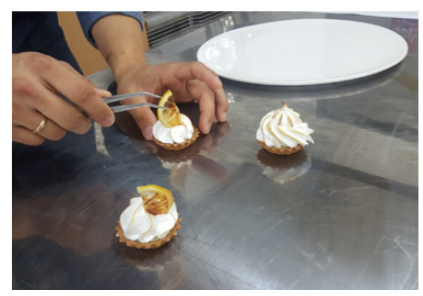

(C)

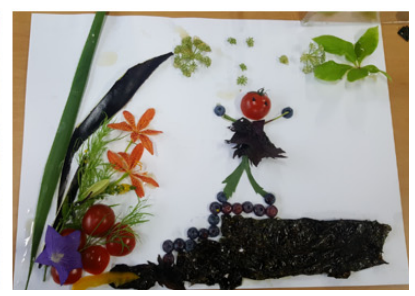

(D)

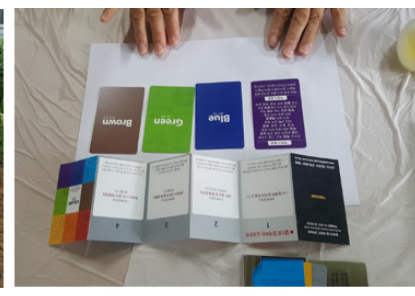

(B)

Fig. 1. Agro-healing activities. (A) Gardening; (B) To get to know myself through color; (C) Making tarts using fermented lemon enzyme; (D) Color food art. 
the total score is 17 or higher, it is Stage 3 (stress is likely to be developed into a mental illness), and when the total score is 19 or higher, it is Stage 4 (respondents need the intervention of professionals). A 5-point Likert scale (0: strongly disagree, 4: strongly agree) was used and Cronbach's $\alpha$ was .888 .

(2) Scale for assessing the satisfaction of participants with the services of the healing farm

In this study, the satisfaction of users with the services of the healing farm was defined as "a way of treating each other as an attitude that people within an organization have towards each other (Parasuraman et al., 1988)." Based on "SERVQUAL" devised by Parasuraman et al. (1988) to measure the level of satisfaction of users with services provided for customers, assessment items were comprised of the following five dimensions: tangibles about the appearance of physical elements; reliability about dependability and accuracy; responsiveness about prompt responses and willingness; assurance about credibility, ability, courtesy and security; and empathy about desired communication, understanding of customers and approaches. To measure the satisfaction of participants in the healing farm program with services in this study, a total of 14 questions were designed and a 5-point Likert scale was used. Cronbach's $\alpha$ of the satisfaction scale in this study was .958 .

\section{(3) Loyalty}

Consumer loyalty means the loyalty that a consumer has when purchasing a product and Smith (1992) defined it as the measure of attachment that a consumer has towards a brand. Loyalty can be measured with the consumer's in- tention to purchase the product again and to revisit the place (Lee, 2003) and is expressed as a consumer's desire to re-purchase a product. It is also defined as a consumer's commitment and can be divided into emotional, cognitive and behavioral loyalty (Oliver, 1999). When participants are satisfied with the activities of the agro-healing program, they have emotional and cognitive loyalty towards and thus intention to revisit the healing farm, and they tend to recommend the program to their acquaintances (Zeithaml et al., 1996). The loyalty scale used in this study was the consumer loyalty scale developed by Gremler (1995), and the scale was revised according to the conditions of the agro-healing program (Table 1). A 5-point Likert scale was used and Cronbach's $\alpha$ of the loyalty scale in this study was .919 .

\section{Content of 1-7 sessions of the agro-healing program provided by the healing farm}

The agro-healing program provided by the healing farm specializing in the functionality of ferment enzymes was operated in the outdoor and indoor spaces of the healing farm once a week, a total of seven sessions (Table 1), for 120 minutes between 15:30 and 17:30. The program was focused on agro-healing activities and was led by professional instructors and assistants. The main operator was the owner of the healing farm (doctor of counseling, healthy family specialist), and a special lecture was provided in each session by a professional instructor. Special lectures were led by the owner of the healing farm (the head of the Ferment Enzyme Research Institute), two professional instructors who majored in gerontology and pedagogy, two

Table 1. Agro-healing activities in a healing farm

\begin{tabular}{cl}
\hline Session & \multicolumn{1}{c}{ Agro-healing activity } \\
\hline 1 & Orientation, a lecture on fermentation \& enzymes and understanding care farm \\
2 & Decorating a straw hat, designing and making(sowing seeds) a vegetable garden \\
3 & Planting seedlings of vegetables and floricultural plants, placing a name tag for plants, safety education, cooking chicken breast \\
& steaks using fermented beet enzyme \\
4 & Planting a pet plant and presenting to me, cooking tarts using fermented lemon enzyme \\
5 & Color food art, gardening a vegetable garden 1 (weeding) \\
6 & Gardening a vegetable garden 2 (learning about the grass), cooking pizza using fermented enzyme \\
7 & Planting and presenting a succulent plant as a gift \\
\hline
\end{tabular}


Eastern and Western food experts and two assistants who majored in horticulture. The overall agro-healing activities including vegetable garden activities were performed by randomly grouping 4-5 participants together, a total of four groups. In the 1st session, participants were informed of the direction of the program and materials to be used and instructors were also introduced. The understanding of fermentation and enzymes was promoted using audiovisual materials, and information on the process of the agro-healing program was provided. Participants introduced themselves and were grouped, and the concept of agro-healing and how to create a vegetable garden were explained. The introduction of the facilities of the healing farm and safety education were also provided, and participants sketched the design of their vegetable garden. After sketching, participants mixed the existing soil in their vegetable garden with a proper amount of bed soil and compost for the sowing and seedling to be performed in the next session. They also had time to experience waiting, patience, the value of labor and the preciousness of life through agro-healing activities. In the 2nd session, a straw hat to be used during activities in the vegetable garden was decorated, and participants with their decorated straw hat on created the vegetable garden of their group based on their sketch and sowed the seeds of summer vegetables including curled mallow, crown daisy and chard. In the 3rd session, seedlings of wrapping vegetables including marigold, salvia, ramie, basil and kale and floricultural plants were planted and the name plates of each group and plant were placed. After that, professional instructors explained the useful functions of fermented beet enzyme in an indoor space, and participants cooked chicken breast steaks using the beet enzyme and shared it together. In the 4th session, participants had time to talk about their favorite flower and why they like the flower, and to understand their preferred color and emotions utilizing color cards. In addition, under the theme of planting and giving a pet plant to myself as a gift, participants planted plants and shared their thoughts. They cooked tartes using fermented lemon enzyme while being informed of the functionality of the lemon enzyme. As a vegetable garden activity, participants weeded out the plants they sowed earlier, and earthed up the plants.

In the 5th session, after hearing know-how about main- taining vegetable gardens, participants performed activities in their vegetable garden as a healing space under the theme of maintaining the vegetable garden as my body. Participants were informed of the nutritional content and functionality of vegetables and fruits based on the classification of phytochemicals, the color of fruits and vegetables, and sketched the design of color food art. Using the prepared vegetables and fruits, they made their work and shared the meaning of their work with others. In the 6th session, under the theme that grasses are not a weed but a medicine, they learned about grasses and their classification and efficacy, maintained their vegetable garden and arranged farming tools. As an indoor activity, they made a healthy pizza using a ferment enzyme. In the 7th session, the last one, under the theme "who is my precious companion?' they learned about how to manage and propagate succulent plants and made their work with succulent plants to express their precious companion. In addition, the vegetables that participants cultivated in their vegetable garden were harvested, and after cleaning up the space used for the program, they shared the advantages and disadvantages of the agro-healing activities and what they felt with each other to wrap up the program.

\section{Statistical analysis}

In this study, statistical analysis was conducted using IBM SPSS ver. 25.0. The reliability of the measurement tools used in this study was analyzed by calculating Cronbach's $\alpha$. The Wilcoxon paired signed ranks test was performed to analyze the level of salivary cortisol and stress, and frequency analysis was performed on satisfaction with services provided by the healing farm, satisfaction with the program and sociodemographic characteristics. In addition, the correlation of satisfaction with services, satisfaction with the program, the level of stress and the level of salivary cortisol with loyalty was analyzed using Pearson's correlation analysis, and the impact of key variables of participants on their loyalty was analyzed using regression analysis. 


\section{Results and Discussion}

\section{General characteristics}

The total number of participants were 18 ( 2 males, 16 females) and their average age was $48.5 \pm 7.55$ years. The share of those in their $50 \mathrm{~s}$ was $50.0 \%$, followed by $40 \mathrm{~s}$ $(38.8 \%)$ and $20 \mathrm{~s}$ and $30 \mathrm{~s}(5.6 \%)$ respectively, and the share of full-time housewives was highest (66.6\%), followed by others $(27.8 \%)$ and professionals (5.6\%). In terms of academic background, the share of those who were college graduates was highest (72.2\%), followed by high school graduates $(22.2 \%)$ and graduate school graduates $(5.6 \%)$, and in terms of the average monthly household income, the share of 2 million won or higher and 1 million won or lower was highest (35.3\%), followed by 4.01 million won or higher (17.6\%), and 1.01-2 million won (11.8\%).

\section{Changes in the cortisol level of participants after participating in agro-healing activities}

Changes in the cortisol level of participants before and after participating in agro-healing activities were examined, and the total average cortisol concentration reduced from $0.084 \mu \mathrm{g} / \mathrm{dL}$ before participating in the agro-healing program to $0.0631 \mu \mathrm{g} / \mathrm{dL}$ after participating in the program, showing the difference of $0.21 \mu \mathrm{g} / \mathrm{dL}(\mathrm{z}=2.809, p<.01$; Table 2). In addition, changes in the concentration of cortisol before and after participating in agro-healing activities were analyzed by session (a total of seven sessions), and the concentration of cortisol after the 2nd-4th, 6th and 7th sessions, except the 1st and 5th sessions, was reduced, showing statistically significant differences. Compared to other sessions, the concentration of cortisol after the 6th session showed a high significance $(p<.001)$ compared to the level before the session (Table 2). Therefore, agroealing activities seem to reduce the concentration of salivary cortisol, a stress hormone. The result of Jang, Gim, et al. (2019) that activities of maintaining a community garden and planting plants significantly reduced the total cortisol concentration of participants is similar to the result of this study that the agro-healing activities reduced the concentration of salivary cortisol, a stress hormone. In addition, the physical actions of agro-healing activities such as plowing the soil, sowing seeds, weeding out and watering plants (Matsuo and Miyajima, 1998) were reported to reduce depression or stress that participants experienced (J.Y. Kim, 2009; Kim, 2013). Jang et al. (2018) reported that the stress level of parents of elementary school students was reduced after participating in a program of cultivating plants, and Ulrich (1981), Kwak (2005) and Lee (2006) also reported that activities of cultivating plants in an artificial space or utilizing natural objects have environmental effects and also emotional effects such as psychological stability, composedness and reduced stress. These results support the result of this study that agro-healing activities reduced the concentration of cortisol, a stress hormone.

Table 2. Changes in cortisol concentrations of participants before and after each session of agro-healing activities

\begin{tabular}{|c|c|c|c|c|c|}
\hline \multirow{2}{*}{ Session } & \multicolumn{2}{|c|}{ Saliva cortisol value $(\mu \mathrm{g} / \mathrm{dL})$} & \multirow{2}{*}{$\mathrm{n}$} & \multirow{2}{*}{$\mathrm{z}$} & \multirow{2}{*}{$p$} \\
\hline & Before & After & & & \\
\hline 1 & $0.05 \pm 0.01^{\mathrm{z}}$ & $0.06 \pm 0.01$ & 16 & -0.673 & $.501^{\mathrm{NS}}$ \\
\hline 2 & $0.07 \pm 0.01$ & $0.05 \pm 0.01$ & 16 & -2.355 & $.019^{*}$ \\
\hline 3 & $0.08 \pm 0.01$ & $0.06 \pm 0.01$ & 17 & -2.187 & $.029^{*}$ \\
\hline 4 & $0.10 \pm 0.01$ & $0.07 \pm 0.01$ & 16 & -2.500 & $.012^{*}$ \\
\hline 5 & $0.09 \pm 0.01$ & $0.07 \pm 0.01$ & 15 & -1.099 & $.272^{\mathrm{NS}}$ \\
\hline 6 & $0.10 \pm 0.01$ & $0.06 \pm 0.01$ & 17 & -3.182 & $.001^{* * *}$ \\
\hline 7 & $0.09 \pm 0.01$ & $0.06 \pm 0.01$ & 17 & -2.367 & $.018^{*}$ \\
\hline Total & $0.08 \pm 0.01$ & $0.06 \pm 0.01$ & 18 & -2.809 & $.005^{* *}$ \\
\hline
\end{tabular}

${ }^{\mathrm{z}}$ Values are mean \pm standard error.

${ }^{\mathrm{NS}}$ Non-significant, ${ }^{*} p<.05,{ }^{* *} p<.01,{ }^{* *} p<.001$ by Wilcoxon Paired Signed Ranks Test $(\mathrm{N}=18)$. 


\section{Changes in the stress level of participants before and after participating in agro-healing activities}

Changes in the stress level of participants before and after participating in agro-healing activities were examined, and 9 out of 10 questions did not show any statistically significant difference. Only Question 8, 'how often do you feel your condition is best?' showed a statistically significant difference. However, the total score of stress after participating in the entire sessions of agro-healing activities was statistically significantly reduced (Table 3 ). When these results were analyzed using the stress level table, the score before the program was the stage of over 18 (stress is likely to be developed into a mental illness) was lowered to the stage of over 16 (respondents have already been affected by stress), showing positive effects. Therefore, the result that agro-healing activities reduced the level of stress in this study can be interpreted that those activities can be useful for reducing the ever-increasing stress and depression observed in the recent COVID-19 outbreak. Urich (1984) and Cimprich (1993) reported that nature has positive effects such as reducing stress, increasing positive emotions and healing patients, and Shin et al. (2007) also reported that the physiological conditions of those with a sense of depression were positively stabilized only with activities of experiencing forests in nature. These studies support the result of this study that the stress level of participants was reduced after participating in agro-healing activities. Jang, Yoo, et al. (2019) also reported that the ratio of alpha to high beta (RAHB) was measured to be high in most points after participating in agro-healing activities and that the ratio was high in T3 (temporal lobe) in charge of motor functions and $\mathrm{O} 2$ (occipital lobe) in charge of visual functions, which indicates that the activities are effective for stabilization and relaxation and supports the results of this study.

\section{Satisfaction of participants in agro-healing activities with services and activities by session}

The satisfaction of participants in the agro-healing program with the services of the healing farm was measured based on the five dimensions suggested by Parasuraman et al. (1988), and the score of responsiveness was highest (4.3/5), followed by assurance, empathy, reliability and tangibles (Fig. 2). Out of the 14 questions on satisfaction that were designed based on the five dimensions, the score of Question 6 on tangibles (employees were willing to help customers) and Question 10 on assurance (employees were polite to customers) was over $4.3 / 5$, showing a high satisfaction level. However, Question 1 on tangibles (facilities in the healing farm were convenient and attractive) and Question 2 on tangibles (signs and materials related to the services of the healing farm were well presented) showed a very low satisfaction level (20-30\%; Table 4$)$. These results indicate that the owner and employees of the healing farm sincerely treated participants but were a little inexperienced in terms of safety, the most important aspect. When participants performed the activities that required tools seemed to have difficulties in locating tools and finding directions and facilities, which demonstrates the im-

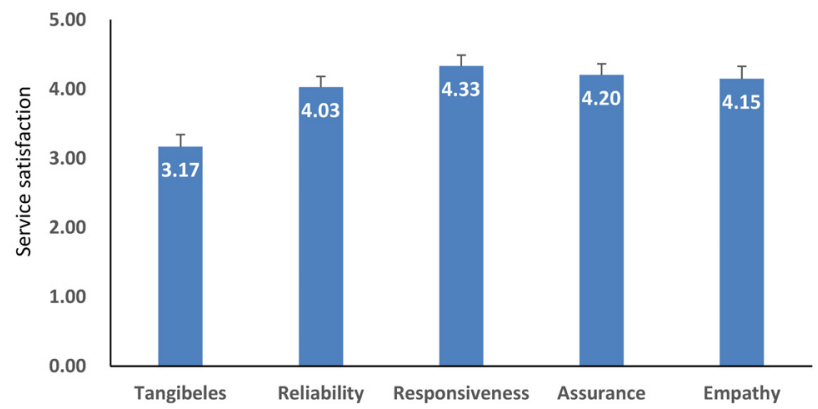

Fig. 2. The satisfaction level of participants in the agrohealing program with the services of the healing farm. Error bars represent the standard error of the mean.

Table 3. Comparison of stress levels of participants before and after entire sessions of agro-healing activities

\begin{tabular}{|c|c|c|c|c|}
\hline & \multicolumn{2}{|c|}{$\mathrm{M} \pm \mathrm{SD}$} & \multirow{2}{*}{ z } & \multirow{2}{*}{$p$} \\
\hline & Before & After & & \\
\hline Stress level & $18.39 \pm 3.71$ & $16.78 \pm 4.60$ & -2.760 & $.003^{* *}$ \\
\hline
\end{tabular}

Note. 5-point Likert scale was used, where $0=$ never; $4=$ always.

${ }^{* *} p<.01$ by wilcoxon paired singed-rank test $(\mathrm{N}=18)$. 
Table 4. Percent of participants' satisfaction with the service of healing farm

\begin{tabular}{cccccc}
\hline Item & Very dissatisfied & Dissatisfied & Neutral & Satisfied & Very satisfied \\
\hline $1^{\mathrm{z}}$ & 11.1 & 11.1 & 55.6 & 22.2 & 0.0 \\
2 & 0.0 & 11.1 & 38.9 & 44.4 & 5.6 \\
3 & 0.0 & 0.0 & 22.2 & 44.5 & 33.3 \\
4 & 0.0 & 0.0 & 33.3 & 30.0 & 16.7 \\
5 & 0.0 & 0.0 & 27.8 & 38.9 & 33.3 \\
6 & 0.0 & 0.0 & 11.1 & 38.9 & 50.0 \\
7 & 0.0 & 0.0 & 11.1 & 50.0 & 38.9 \\
8 & 0.0 & 0.0 & 11.1 & 50.0 & 38.9 \\
9 & 0.0 & 5.5 & 16.7 & 50.0 & 27.8 \\
10 & 0.0 & 0.0 & 11.2 & 44.4 & 44.4 \\
11 & 0.0 & 0.0 & 16.7 & 44.4 & 38.9 \\
13 & 0.0 & 5.6 & 5.6 & 44.4 & 44.4 \\
\end{tabular}

Note. 5-point Likert scale was used for the survey $(\mathrm{N}=18)$.

${ }^{\mathrm{z}}$ Service satisfaction questions. $1=$ The care farm's facilities are convenient and attractive; $2=$ Signs and materials related to the services of the healing farm were well presented; $3=$ A timely response was provided to customer's question or request; $4=$ The care farm and it's staffs fulfilled the contracts well; $5=$ Service records, charges and other items were provided correctly; $6=$ Staffs were willing to help customers; $7=$ Staffs responded promptly to the customer's demands; $8=$ Staffs were trustworthy; $9=$ Care farm's services were stable and relaxed; $10=$ Staffs were polite to customers; $11=$ Staffs were well aware of the customer's needs; $12=$ Care farms try to protect customers' interests; $13=$ Services required by customers were provided; $14=$ Services of care farm have met my needs.

portance of properly installed signs on safety and facilities. Most participants showed a high desire for services due to the difficulties they faced in reality, while the owner of the healing farm who provided services for participants seemed to view the personality issues of participants are more important and tend to view changes in the personality of participants more important in solving problems. These differences in perception between them can result in differences in the perception of desires for services between participants and healing farm owners (Jeong, 2003). Therefore, it can be concluded that satisfaction with services is significantly affected by how healing farm owners and participants perceive services.

In addition, the satisfaction of participants with the agro-healing program by session was surveyed, and the score in the 1st session was lowest (4), but the score continued to increase from the 2 nd session. The score of the 3rd-7th sessions was high (4.5/5; Fig. 3). In particular, from the 3rd session, 'satisfied' and 'very satisfied' accounted for nearly over $95 \%$ (Table 5). The high satisfaction of

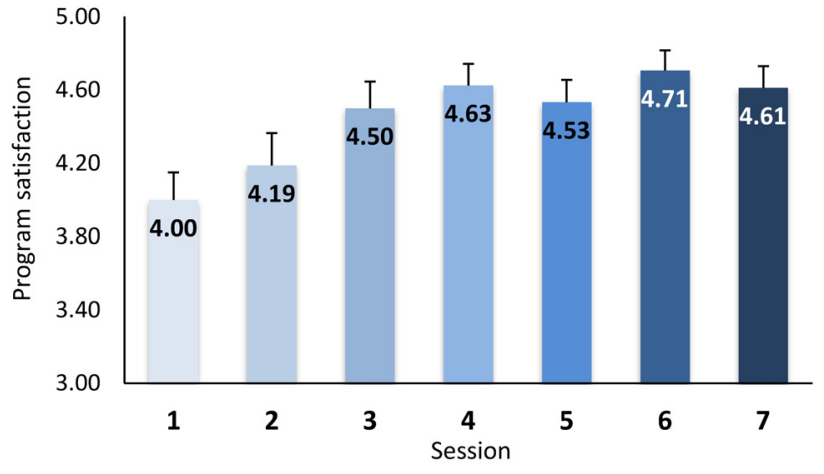

Fig. 3. The satisfaction level of participants with the agrohealing program by each session. Error bars represent the standard error of the mean.

participants can be attributed to the content of the program designed according to the characteristics and environment of the healing farm. This result was similar to the result of Jang, Yoo, et al. (2019) that the satisfaction of patients with high blood pressure and diabetes, chronic life style diseases, with the sessions of the agro-healing program conducted in a healing farm was very high. 
Table 5. Percent of participants' satisfaction with each session in agro-healing program

\begin{tabular}{cccccc}
\hline Session & Very dissatisfied & Dissatisfied & Neutral & Satisfied & Very satisfied \\
\hline 1 & 0.0 & 0.0 & 18.8 & 62.5 & 43.7 \\
2 & 0.0 & 0.0 & 18.8 & 3.7 & 37.5 \\
3 & 0.0 & 0.0 & 0.6 & 37.5 & 55.6 \\
4 & 0.0 & 0.0 & 0.0 & 48.7 & 62.5 \\
5 & 0.0 & 0.0 & 0.0 & 29.4 & 53.3 \\
7 & 0.0 & 0.0 & 0.0 & 38.9 & 70.6 \\
\end{tabular}

Table 6. Correlation between cortisol level, satisfaction, stress level and loyalty of participants

\begin{tabular}{|c|c|c|c|c|c|}
\hline & Loyalty & Cortisol concentration & Service satisfaction & Program satisfaction & Stress level \\
\hline Loyalty & 1 & & & & \\
\hline Cortisol concentration & .213 & 1 & & & \\
\hline Service satisfaction & $.703^{* *}$ & -.023 & 1 & & \\
\hline Program satisfaction & .466 & -.161 & .395 & 1 & \\
\hline Stress level & .141 & -.160 & .367 & .139 & 1 \\
\hline
\end{tabular}

${ }^{* *} p<.01(\mathrm{~N}=18)$.

\section{Correlation of the satisfaction and stress level of participants with their loyalty}

The correlation of the cortisol, satisfaction and stress level of participants in agro-healing activities with their loyalty was examined, and their satisfaction with services showed a high positive correlation (over .7) with their loyalty, which was statistically significant. The level of cortisol, satisfaction with the program and the level of stress showed a positive correlation with loyalty, while the level of cortisol showed a negative correlation with satisfaction with services, satisfaction with the program and the level of stress (Table 6). However, there was no statistically significant difference. These results indicate that key variables such as the satisfaction of participants with the services of the healing farm significantly affected their intention to revisit the farm.

\section{Effects of key variables on loyalty}

The effects of the concentration of cortisol, satisfaction with services, satisfaction with the program and the level of stress on loyalty were examined, and the four variables including cortisol, satisfaction with services, satisfaction with the program and the level of stress explained $61 \%$ of loyalty. The $\mathrm{F}$ value was 5.18 , and data were statistically significant at the level of 0.01 , indicating that the key variables of participants including the level of stress and satisfaction with services and the program have strong effects on loyalty (Table 7). Lee (2007) reported that contacting with natural environments restore the ability of attention, reduce the negative effects of stress and thus improve emotions, which supports the usefulness of the results of this study that the concentration of cortisol after participating in agro-healing activities, satisfaction with services and the program and the level of stress affected the loyalty of participants.

\section{Conclusion}

To examine the effects of the resources of a healing farm and the satisfaction of participants on the level of stress and loyalty, this study measured the level of salivary cortisol and surveyed the level of stress, satisfaction with the services of the healing farm and satisfaction with the program, targeting a total of 18 males and females (aged 
Table 7. The effect of cortisol level, service satisfaction, program satisfaction and stress level on loyalty

\begin{tabular}{lccccc}
\hline \multicolumn{1}{c}{ Independent variable } & $\mathrm{B}$ & $\beta$ & $\mathrm{t}$ & $\mathrm{R}^{2}$ & $\mathrm{~F}$ \\
\hline (Constant) & -1.55 & & & & \\
Cortisol concentration & 8.65 & 0.26 & 1.45 & 0.61 & 5.18 \\
Service satisfaction & 0.84 & 0.64 & $3.17^{* *}$ & \\
Program satisfaction & 0.51 & 0.27 & 1.41 & -0.47 & \\
Stress level & -0.04 & -0.09 &
\end{tabular}

Note. Dependent variable: loyalty. Loyalty was rated on 5-point scale, where $1=$ strongly disagree, $5=$ strongly agree.

Loyalty item; 1 = Be able to talk positively to other people about agro-healing experience; $2=$ After visit this place, I am willing to try the agro-healing experience again; 3 = Strongly recommend agro-healing experience to relatives or friends.

${ }^{* *} p<.01(\mathrm{~N}=18)$.

49.5 \pm 7.55 years on average). Agro-healing activities were performed once a week, a total of seven sessions, for 90 minutes and the items above were measured before and after participating in the program. Differences before and after participating in agro-healing activities were compared and analyzed, and the concentration of cortisol, a stress hormone, was reduced after participating in 5 sessions out of 1-7 sessions, and the total concentration of cortisol after participating in agro-healing activities showed statistically significant differences $(\mathrm{z}=-2.809, p<.01)$. Compared to other sessions, the 6th session composed of understanding grasses (weeds), maintaining a vegetable garden and making and sharing a pizza with enzymes showed the lowest concentration of cortisol after participating in agro-healing activities compared to the level before participating in the activities $(\mathrm{z}=-3.182, p<.001)$, indicating that agro-healing activities are effective in reducing the level of stress. The level of stress was surveyed using 10 questions, and the level decreased from 18.39 to 16.78 statistically significantly $(\mathrm{z}=-2.760, p<.01)$, supporting a decrease in the concentration of cortisol, a stress hormone. The satisfaction of participants in agro-healing activities with the services of the healing farm was surveyed after the final session, and out of 14 questions, 2 questions about the convenience of facilities and the placement of signs and materials showed a low satisfaction level on average, $50 \%$ or lower, which demonstrates that education and promotion are essential for the owner of healing farms on the convenience of facilities in healing farms, signs and safety. However, the overall satisfaction of participants with the program comprised of 7 sessions was high (over 4), and the satisfaction of participants with the program tended to increase as participants attended more sessions. The correlation of the satisfaction of participants and the level of stress with loyalty was also analyzed, and satisfaction with the services of the healing farm and loyalty showed a very positive correlation, which was statistically significant. In addition, the effects of the key variables of participants on their loyalty were analyzed, and the level of stress and satisfaction with services and the program were found to have a strong influence on loyalty. Jang, Gim, et al. (2019) reported that the level of stress was lowered from the level of being likely to be developed into a mental illness before participating in the activity of maintaining a community garden to the level of having been already affected by stress after participating in the activity, and thus that the program comprised of plant cultivation activities was effective in reducing the level of stress that participants experienced. Jang et al. (2018) also reported that the level of cortisol, a stress hormone, of parents of elementary school students was statistically significantly reduced after participating in plant cultivation activities, indicating that plant cultivation activities positively affect their healing effects. These results support the result of this study that the concentration of cortisol, a stress hormone, and the level of stress were reduced. Since the Agro-healing Act was passed recently, people's interest in healing farms and agro-healing has increased, but only a limited amount of information on agro-healing activities provided by healing farms is available. Therefore, it will be necessary to continuously research information on agro-healing and healing farms and their effects. 


\section{References}

Baek, Y.M. 2010. Korean version of the perceived stress scale-10: Development of the scale and exploring the effects of perceived stress on memory. Master's thesis, Seoul National University, Seoul, Korea.

Braastad, B.O., C. Gallis, J. Sempik, S. Senni, and T. van Elsen. 2007, June. COST Action 866 "Green care in agriculture": A multi-disciplinary scientific network. Proceedings of COST Action 866 Conference "Green care in agriculture: Health effects, economics and policies (pp. 13-24)", Austrian Horticultural Society, Vienna, Austria.

Choi, K.S. and K.C. Kim. 2002. A study on the supportive design conditions for the hospital stress in Korea. J. Korean Inst. Healthc. Archit. 8(1):61-67.

Choi, S., I. Lee, I. Song, O.J. Kwon, K. Park, H. Hong, K.K. Sung, and S. Lee. 2014. Method of saliva collection for salivary cortisol measurement. Korean J. Orient. Physiol. Pathol. 28(2):223-232. https://doi.org/10.15188 /kjopp.2014.04.28.2.223

Cimprich, B. 1993. Development of an intervention to restore attention in cancer patients. Cancer Nurs. 16(2): 83-92.

Cohen, S. and G.M. Williamson. 1988. Perceived stress in a probability sample of the United States. In: S. Spacapan and S. Oskamp (Eds.), The Social Psychology of Health (pp. 31-67). Newbury Park, CA: Sage.

Davis, M. and E. Emory. 1995. Sex differences in neonatal stress reactivity. Child Dev. 66(1):14-27. https://doi.org/ 10.1111/j.1467-8624.1995.tb00852.x

Finkelstein, N.G. 2003. The holocaust industry: Reflections on the exploitation of Jewish suffering (2nd ed.). NY, USA: Verso.

Gremler, D.D. 1995. The effect of satisfaction, switching costs, and interpersonal bonds on service loyalty. Doctoral dissertation, Arizona State University, Arizona, USA.

Im, K.B. 1997. Factors of stress by job type in hospital organization, impact on internal customer satisfaction and organizational immersion. Master's thesis, Yeungnam University, Gyeongbuk, Korea.

Jang, H.S., G.M. Gim, S.J. Jeong, and J.S. Kim. 2018. Effects of plant cultivating activity for reducing parental stress. J. People Plants Environ. 21(3):203-211. https://doi.org/10.11628/ksppe.2018.21.3.203

Jang, H.S., G.M. Gim, S.J. Jeong, and J.S. Kim. 2019. Community gardening activities and their effects on mental health of residents. J. People Plants Environ. 22(4):333-340. https://doi.org/10.11628/ksppe.2019.22. 4.333

Jang, H.S., E.H. Yoo, S.J. Jeong, J.S. Kim, and D.Y. Ryu. 2019. Effects of an agro-healing activity program on the physiological condition of adults with chronic metabolic diseases. J. People Plants Environ. 22(4):355-364. https://doi.org/10.11628/ksppe.2019.22.4.355

Jeong, W.C. 2003. Recognition of service needs of the mentally ill and the mental service providers and factors affecting service needs of the mentally ill in community mental rehabilitation center. Ment. Health Soc. Work 16(12):156-179. Retrieved from https://www.kamhsw.org

Kim, H.Y. 2013. Effects of community garden construction and horticultural activities on the life-satisfaction of rural residents. Doctoral dissertation, Chungnam National University, Taejon, Korea.

Kim, J.Y. 2009. Age and depression in Korean adults. Health Soc. Sci. 26:89-113. Retrieved from http://kahms.re.kr

Kim, K.H. 2009. A study on characteristics of healing environment in the late work of Frank Lloyd Wright. J. Korean Inst. Healthc. Archit. 12(1):41-48.

Kwak, S.O. 2005. A study on the environmental marketing for interiorscape within apartment. Doctoral dissertation, Sangmyung University, Cheonan, Korea.

Kwon, S.Y. 2015. A study on the healing experience in a garden with a perspective of cognitive response mechanism. Master's thesis, Hongik University, Seoul, Korea.

Lee, G.G. 2006. Visual preference in green roof sites. J. Korean Inst. Landsc. Archit. 34(5):32-38.

Lee, J.Y. 2003. Effects of air transportation service delay on customer satisfaction, relationship quality, and customer loyalty. Doctoral dissertation, Gyeongiu University, Gyeongju, Korea.

Lee, S.H. 2007. The effects of the index of greenness simulation based restorative environment model upon emotion improvement. Korean J. Health Psychol. 12(2):439-465.

Loue, S. 2016. CooperRiis healing community. In: Therapeutic farms: Recovery from mental illness. Switzerland: Springer. https://doi.org/10.1007/978-3-319-13539-7_5 
Matsuo, E. and I. Miyajima. 1998. Up-to-date trend of horticultural therapy in Japan: An attempt to redefine horticulture in horticultural therapy and place horticultural therapy in relation to other therapies. J. Korean Soc. People Plants Environ. 1(1):22-33.

McKenzie-Mohr, D., L.S. Nemiroff, L. Beers, and S. Desmarais. 1995. Determinants of responsible environmental behavior. J. Soc. Issues 51(4):139-156. https://do i.org/10.1111/j.1540-4560.1995.tb01352.x

Oliver, R.L. 1999. Whence consumer loyalty? J. Mark. 63:33-44. https://doi.org/10.2307/1252099

Parasuraman, A., V.A. Zeithaml, and L.L. Berry. 1988. A multiple- item scale for measuring consumer perceptions of service quality. J. Retailing 64(1):12-40.

Park, H.C. and D.K. Kang. 2017. Suggestions for applications of therapeutic farms for promoting school community engagement in Korea based on review of therapeutic farms, gardens, animals, policies, and laws in the U.S.A. J. Rural Soc. 27(2):215-269. https://doi.org/10.31894/JR S.2017.12.27.2.215

Relf, P.D. 1990. Psychological and sociological response to plants: Implications for horticulture. HortScience 25(1):11-13. https://doi.org/10.21273/HORTSCI.25.1.11

Schwartz, E.B., D.A. Granger, E.J. Susman, M.R. Gunnar, and B. Laird. 1998. Assessing salivary cortisol in studies of child development. Child Dev. 69(6):1503-1513.

Shin, W.S., P.S. Yeoun, and J.H. Lee. 2007. The impact that a forest experience influences on a human mental state stability. J. Korean Inst. For. Recreat. 11(3):37-43.

Smith, D.C. 1992. Managing brand equity: Capitalizing on the value of a brand name by David A. Aaker [review of the book Managing brand equity: Capitalizing on the value of a brand name by D.A. Aaker]. J. Mark. 56(2):125-128. https://doi.org/10.2307/1252048

Ulrich, R.S. 1981. Natural versus urban scenes: Some psychophysiological effects. Environ. Behav. 13(5):523-556. https://doi.org/10.1177/0013916581135001

Ulrich, R.S. 1984. View through a window may influence recovery from surgery. Science 224(4647):420-421. https://doi.org/10.1126/science.6143402

Ulrich, R.S. 1986. Human responses to vegetation and landscapes. Landsc. Urban Plan. 13:29-44. https://doi.or g/10.1016/0169-2046(86)90005-8

Ulrich, R.S., R.F. Simons, B.D. Losito, E. Fiorito, M.A. Miles, and M. Zelson. 1991. Stress recovery during exposure to natural and urban environments. J. Environ. Psychol. 11(3):201-230. https://doi.org/10.1016/S02724944(05)80184-7

Yamaguchi, M., M. Deguchi, and Y. Miyazaki. 2006. The effects of exercise in forest and urban environments on sympathetic nervous activity of normal young adults. J. Int. Med. Res. 34(2):152-159. https://doi.org/10.1177/ 147323000603400204

Zeithaml, V.A., L.L. Berry, and A. Parasuraman. 1996. The behavioral consequences of service quality. J. Mark. 60(2):31-46. https://doi.org/10.2307/1251929 